\title{
Personalized learning plans for pre-requisite materials in a senior-level traffic engineering course
}

\section{Dr. Vikash Gayah, The Pennsylvania State University}

Dr. Vikash V. Gayah is an associate professor in the Department of Civil and Environmental Engineering at The Pennsylvania State University (joined 2012). He received his B.S. and M.S. degrees from the University of Central Florida (2005 and 2006, respectively) and his Ph.D. degree from the University of California, Berkeley (2012). Dr. Gayah's research focuses on urban mobility, traffic operations, traffic flow theory, traffic safety and public transportation. His research approach includes a combination of analytical models, micro-simulations and empirical analysis of transportation data. He has authored over 50 peer-reviewed journal articles, over 50 refereed conference proceedings, and numerous research reports to sponsors. He has worked on research contracts valued at more than $\$ 5$ million, sponsored by the Pennsylvania, Washington State, Montana and South Dakota Departments of Transportation, US Department of Transportation (via the Mineta National Transit Research Consortium and the Mid-Atlantic Universities Transportation Center), Federal Highway Administration, National Cooperative Highway Research Program and National Science Foundation.

Dr. Gayah currently serves as an editorial advisory board member of Transportation Research Part C: Emerging Technologies, an editorial board editor of Transportation Research Part B: Methodological, an associate editor for the IEEE Intelligent Transportation Systems Magazine (an international peer-reviewed journal), a handling editor for the Transportation Research Record and is a member of the Transportation Research Board's Committee on Traffic Flow Theory and Characteristics (AHB 45), where he serves as a paper review coordinator. He has been recognized with multiple awards for his research and teaching activities, including the Dwight D. Eisenhower Transportation Fellowship, Gordon F. Newell Award for Excellence in Transportation Science, University of California Transportation Center Student of the Year Award, New Faculty Award by the Council of University Transportation Centers, the Cunard, Fred Burggraf and D. Grant Mickle outstanding paper awards by the Transportation Research Board, Harry West Teaching Award by the Department of Civil and Environmental Engineering at Penn State, Outstanding Teaching Award by the Penn State Engineering Alumni Society, and Faculty Early Career Development (CAREER) Award by the National Science Foundation.

\section{Dr. Sarah E Zappe, Pennsylvania State University, University Park}

Dr. Sarah Zappe is Research Professor and Director of Assessment and Instructional Support in the Leonhard Center for the Enhancement of Engineering Education at Penn State. She holds a doctoral degree in educational psychology emphasizing applied measurement and testing. In her position, Sarah is responsible for developing instructional support programs for faculty, providing evaluation support for educational proposals and projects, and working with faculty to publish educational research. Her research interests primarily involve creativity, innovation, and entrepreneurship education.

\section{Dr. Stephanie Cutler, Pennsylvania State University}

Stephanie Cutler has a Ph.D. in Engineering Education from Virginia Tech. Her dissertation explored faculty adoption of research-based instructional strategies in the statics classroom. Currently, Dr. Cutler works as an assessment and instructional support specialist with the Leonhard Center for the Enhancement of Engineering Education at Penn State. She aids in the educational assessment of faculty-led projects while also supporting instructors to improve their teaching in the classroom. Previously, Dr. Cutler worked as the research specialist with the Rothwell Center for Teaching and Learning Excellence Worldwide Campus (CTLE - W) for Embry-Riddle Aeronautical University. 


\title{
Personalized learning plans for prerequisite materials in a senior-level traffic engineering course
}

\begin{abstract}
The purpose of this project was to improve a senior-level elective course on Traffic Operations at the Pennsylvania State University. Previous experiences with the course suggested that students generally have very poor recollection of various topics in statistics, which are required to appropriately analyze field data. Because of these deficiencies in prerequisite material, a significant portion of the course (about 4-5 of 30 lecture sessions) was spent reviewing background material. Doing so reduced the time available to spend on new material related to the course topic, broke momentum during the semester, and tended to be disengaging for students who did have sufficient background knowledge.
\end{abstract}

Through a project with the Leonhard Center for Enhancement of Engineering Education within the College of Engineering, data-driven methods were developed to assess student competencies on this background material and provide personalized instructional modules to address any deficiencies. A pre-test on the prerequisite statistics material was created based on six unique topics that were deemed important to the course material. Students were asked to take the pretest during the first week of the course and their responses were used to provide them with targeted outside-of-the-classroom learning modules based on the specific material that they struggled with. Specifically, each question was associated with a unique module and a student only had to complete a module if they missed the associated question. These modules were comprised of reading assignments, YouTube videos and additional practice problems. Students were asked to turn in the additional problems for class credit. However, the problems themselves were not graded but were used to ensure students completed the necessary activities. During the fourth week, students were then asked to take a post-test to assess their knowledge of the prerequisite material, as well as their improvement on the topics that were most challenging.

The results suggested that the targeted modules helped improve performance on the prerequisite material by about $40 \%$ on average and that student confidence in their abilities increased by about $45 \%$. Moreover, moving the prerequisite material outside of the classroom helped free up additional time to cover topics related to the course material that could not be accommodated before, including signal coordination and actuated signal control. In general, this strategy appears to be effective and can be applied to any course to help address issues with prerequisite knowledge. This study is limited due to the relatively low sample size (total of 81 students), lack of a comparison group to compare traditional methods of teaching prerequisite material, and potential confounding factors that might have influenced results. However, the large improvements in performance and short-time frame that this was implemented in may help limit some of these impacts. 


\section{Introduction}

Most engineering courses build upon material that students are expected to have learned in previous courses [1]. Prerequisites are used to ensure that students entering a given course are adequately prepared for the material that they will learn in an upcoming course [2], [3]. The use of prerequisites helps to ensure that instructors can focus on new material and build upon a student's existing knowledge base, as opposed to continuing to review material that they should have known.

However, students have varying degrees of proficiency with prerequisite material when entering a given class [4]. Some of this is due to variations in preparation. Some prerequisite courses may be taught by different instructors, who have different levels of effectiveness in providing this material [5]. Different courses may serve as a prerequisite and variations within the individual prerequisite courses can lead to differences in student preparation. Differences can also occur due to when students take these prerequisite courses: in some cases students take courses in direct sequence, while in others students may have taken a prerequisite years before the course that they will actually need that information in. Recent studies suggest that engineering student's retention of critical mathematical and other knowledge tends to fade over time - and sometimes does so significantly [6]-[8] — especially if they are not actively engaged with the material during that time [9].

Due to the varying degrees in proficiency in prerequisite material, instructors must often review the prerequisite material sometime during a course to help ensure that students have a more uniform background and are prepared to learn more advanced material. Reviewing this material encourages students to practice retrieving information that they previously learned, which has been shown to help them remember that information longer than simply restudying [10]. However, while effective, reviewing prerequisite material within a course can have negative side effects on the overall course structure. For one, it reduces the amount of time that can be spent on new material related to the course topic. It may also reduce the amount of time that can be dedicated to more engaging active learning activities. When prerequisite material is reviewed during the semester, it can break course momentum. And finally, this review tends to be boring/disengaging for students who do have sufficient background knowledge.

This study examines the effectiveness of outside-the-classroom online modules to help students address deficiencies in knowledge of prerequisite material. Similar methods were recently applied to help students review material for a design course [11]. Unique to this work, however, is that data-driven instructional techniques were used to identify individual student competencies on these background topics and provide personalized instructional plans that each student needed to perform to address any deficiencies. Activities assigned to each student were personalized based on their existing proficiency in the prerequisite material at the beginning of the semester, assessed using a pre-test. The effectiveness of this intervention was assessed by comparing student proficiency and confidence in the material using a post-test, as well as the amount of time that was saved from reviewing this prerequisite material during the lecture and students responses obtained in teaching evaluations. 
The remainder of this paper is organized as follows. First, the research methodology is described. Then, the study results are presented. Finally, discussion and concluding remarks are provided.

\section{Methodology}

\section{Research questions}

This study seeks to answer the following research questions:

1. Can students adequately address areas of weaknesses in prerequisite material on their own through outside-of-the-classroom interventions?

2. Would removing coverage of prerequisite material from the classroom cause students to become more engaged in the actual course content?

\section{Methods and data collection}

This study focused on removing the teaching of prerequisite material in statistics from a seniorlevel undergraduate course in traffic engineering (CE 423) at the Pennsylvania State University. A pre-test was developed to assess each student's baseline knowledge of prerequisite material that would have been covered in previous courses. The pre-test covered six unique topics in statistics:

1. Descriptive statistics

2. Summing random variables

3. Standard normal distribution

4. Confidence intervals

5. Z-test of equality

6. Chi-square test

Students were expected to have learned these topics through their general education requirements for the civil engineering major. However, one issue with this was that most students take their statistics course very early in their college career (usually first or second year), whereas the course considered here is a senior-level course. Thus, there is considerable time between when the students first learn this material and when they must apply it in the course. Another issue is that there are different courses that can be used to satisfy the statistics requirement and anecdotal evidence suggests that they cover this material with varying degrees of success. For these reasons, individual students have significant variation in their proficiency of this material when entering

Each of the six topics were mapped to a specific question or set of questions on the pre-test. The questions were open-ended and students were required to provide a numerical answer to each question. As an example, the question focused on descriptive statistics provided students with a set of 50 numbers and students were asked to provide the mean, median, mode, standard deviation and variance of the data. Another question provided the mean and standard deviation 
of two data sets (one in a before period, one in an after period) and students were asked to estimate the z-value for a Z-test of equality, the critical z-value that would be associated with a statistical test at the $95 \%$ confidence level, and answer (yes or no) if the change between the before and after periods was statistically significant at the $95 \%$ confidence level. The pre-test was open book and students were allowed to use outside material or software, such as the internet or Microsoft Excel to answer any of the questions. This was done since the test was assessing prior knowledge and the ability to apply these concepts to real data, which would be needed for the course. In addition to providing the technical answer to these questions, students were also asked to provide their level of confidence in their answer to each question on a 1-10 scale. The pre-test was administered using the Canvas course management platform and was automatically graded.

Responses to the pre-test were then used to identify areas of weakness for each student within these six topic areas and develop personalized learning plans to overcome these areas of weakness. These lesson plans consisted of a subset of six learning modules related to the prerequisite material that students were required to complete outside of the classroom. Each topic covered on the pre-test was associated with a specific module and students were only assigned complete the modules associated with corresponding question(s) that they did not answer correctly. For example, if a certain student correctly answered the questions on descriptive statistics and summing variables, they were then only assigned the modules associated with the standard normal distribution, confidence intervals, z-test of equality and chi-square test. Each of the modules were comprised of a combination of:

- reading assignments from the course textbook;

- YouTube videos;

- example problems with solutions; and,

- additional practice problems.

The material was identified to ensure adequate coverage of the material in a manner that was associated with the course content. For that reason, readings were generally taken from the course textbook (Traffic Engineering, $4^{\text {th }}$ edition by McShane, Prassas and Roess [12]). Example problems were developed by the course instructor to demonstrate applicability of the topics to the course, as would have been the case if the content was covered within the course lectures. Solutions to these example problems were also provided to demonstrate how these topics are applied to these realistic problems. YouTube videos were more general and were selected based on graphical content and quality of explanation. The modules were distributed using Canvas and each student had access to all modules, even though they were only assigned a subset of the modules to complete.

Participants in this study were senior-level civil engineering students taking an elective course on traffic engineering. The course was taught once annually, and enrollment was typically 20-30 students per year. During each of these course offerings, students were required to take the statistics pre-test during the first week of class. The pre-test was given during the course lab period and was announced ahead of time, to alleviate student displeasure that was noted in a related study to occur otherwise [11]. Unlike the previous study, the pre-test was graded and students were informed that the grade would count towards their quiz scores for the semester. 
Upon completing the pre-test, each student had the option to change their actual score on the pretest to a perfect score by adequately completing the modules assigned to them based on their performance on the pre-test. Adequate completion was assessed by the successful (but not necessarily correct) completion of the practice problems associated with each module within a certain time period (three weeks of the pre-test). Students were required to complete only the modules for which they were identified as having weakness in based on responses to the pre-test. Note that students were not informed ahead of time that they would be able to turn their pre-test score into a perfect score by completing outside-of-the-classroom activities to ensure that they were fully motivated to try their best on the pre-test. This format provided incentive to students to complete the outside-of-the-classroom modules on prerequisite material, while not penalizing students that may not have had a strong background in the prerequisite material. However, all students had access to all six modules in case they wished to refresh their knowledge on topics that they exhibited sufficient proficiency.

During the fourth week of the semester, students were then asked to take a post-test to assess their knowledge of the prerequisite material. The post-test was announced ahead of time and actually contained the same questions as the pre-test, as well as questions on student confidence in the material. This facilitated direct before/after comparisons of proficiency in the material due to the personalized learning plans, although it should be noted that this might create bias in comparison. Statistics material was not practiced or discussed within the classroom before the post-test to ensure that all changes were a result of the proposed interventions. The post-test was graded and counted as a quiz for the semester to ensure students took it seriously. Like the pretest, the post-test was administered online using the Canvas course management platform. The test was also open book and students were allowed to access to additional material while taking it. This included access to the outside-of-the-classroom modules. However, since the questions were the same, students were not provided access to their answers on the pre-test while taking the post-test. Students were also monitored to ensure that they were not actively communicating with other students (both inside and outside of the classroom) during this test.

The proposed activities were performed three times, once per year from 2017 to 2019 . A total of 81 students participated and agreed to have their scores used in this study: 29 in 2017, 30 in 2018 and 22 in 2019.

\section{Data analysis}

The first research question was answered by comparing student responses to the pre- and posttests. Proficiency was observed by comparing the technical correctness of the answers, while confidence in the material was assessed using the student-reported confidence values to the preand post-test questions. Paired t-tests were used to examine the magnitude and statistical significance of changes across individual students (identified using a randomly generated student ID) in proficiency of the technical material and confidence in applying the material. 
The second research question was assessed based on the number of class periods that did not have to be dedicated to teaching prerequisite material, the additional topic areas that could be taught during the semester and student responses in student evaluations of teaching performance.

\section{Results}

The remainder of this section describes how the personalized learning plans influence student proficiency and confidence in the prerequisite material, as well as overall course outcomes.

\section{Student proficiency and confidence in prerequisite material}

Figure 1 provides average proficiency scores within the six subject areas on both the pre-test and post-test of students within each of the three semesters that the personalized outside-of-theclassroom activities were applied. An examination of pre-test scores showed that students exhibited a very good level of proficiency on two topic areas: Descriptive statistics (average of 4.43 out of a possible 5.0) and Summing random variables (average of 3.67/5.0).. However, students exhibited very low levels of proficiency on the remaining topic areas: Standard normal distribution (average of 1.54/5.0), Confidence intervals (average of 1.36/5.0), Z-test of equality (average of 1.40/5.0), and Chi-square test (average of 0.63/5.0). Focusing on the post-test scores, the results revealed that proficiency in nearly all topics increased to adequate levels (average of greater than 2.5/5.0) in all topic areas except for Confidence intervals (average of 1.82/5.0).

Comparison between the pre-test and post-test scores reveal that that average scores within each topic increased between the pre- and post-tests due to the intervention. The lone exception is the Topic 1 during the Fall 2019 semester, which observed a decrease in proficiency. However, this decrease was extremely small (average of 4.45 in the pre-test to 4.27 in the post-test) and, as will be discussed later, was not found to be statistically significant. Focusing on the entire group of 81 students that received the intervention, the proposed intervention increased proficiency levels by the following amounts:

1. Descriptive statistics - Increase of $5 \%$

2. Summing random variables - Increase of $8 \%$

3. Standard normal distribution - Increase of $108 \%$

4. Confidence intervals - Increase of $34 \%$

5. Z-test of equality - Increase of $103 \%$

6. Chi-square test - Increase of $359 \%$

In general, the results show only modest increases in areas in which students were exhibited strong proficiency levels before the intervention. However, except for Topic 4, the intervention at least doubled proficiency levels in all other topics.

Post-test proficiency scores were compared to scores on similar questions on homework assignments that were taken during previous semesters when this prerequisite material was directly included in the course lectures. Only five of the six topic areas had questions that were 


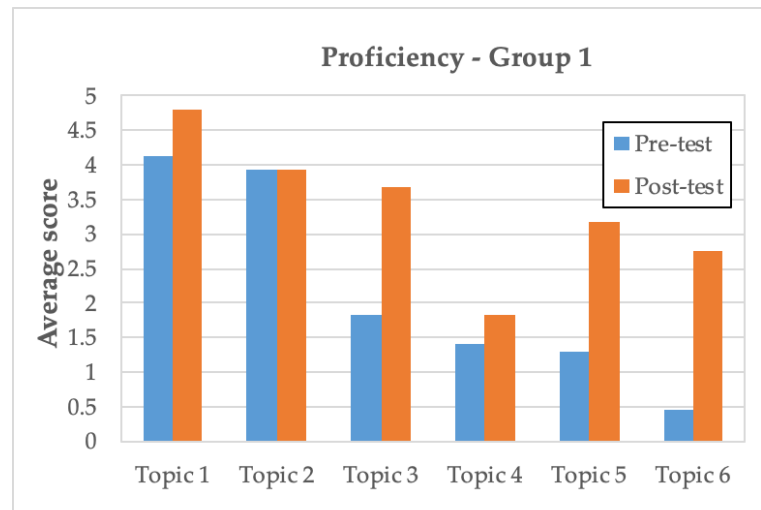

(a)

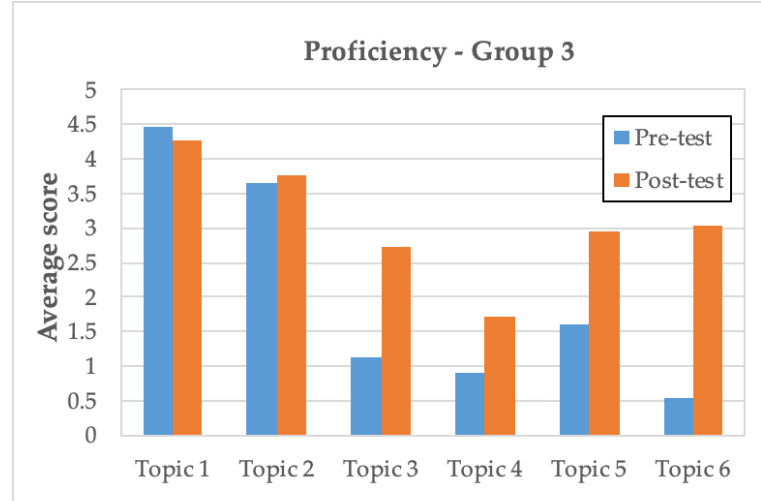

(c)

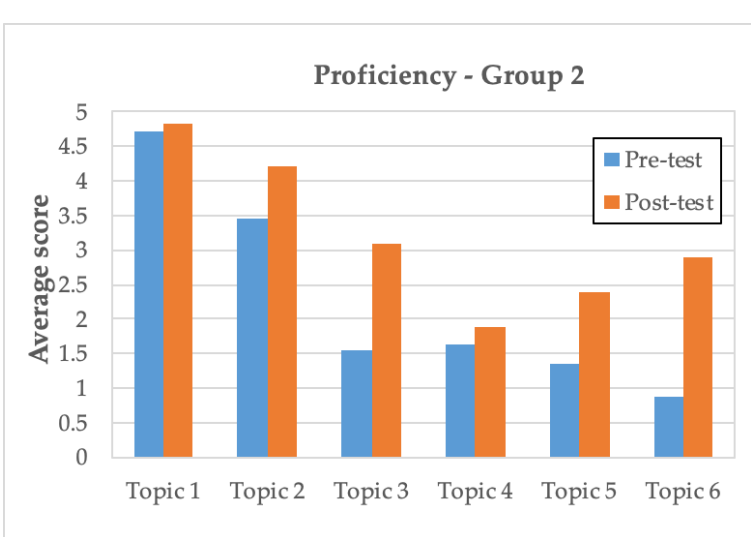

(b)

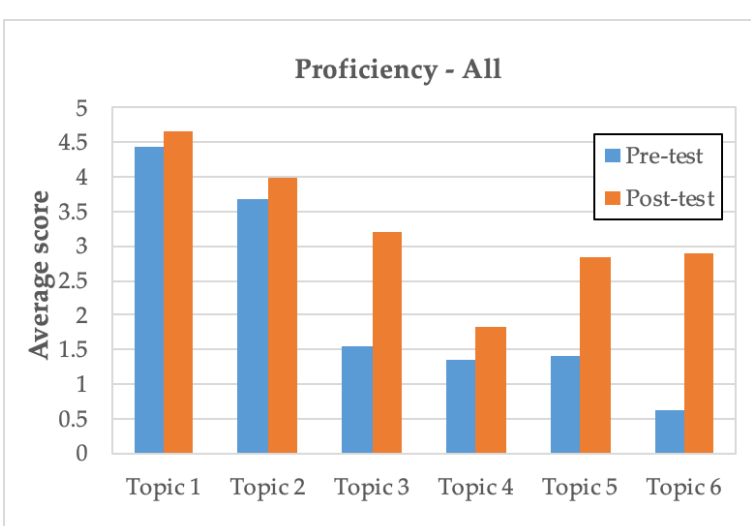

(d)

Figure 1. Comparison of student proficiency scores within the various subject areas between pre- and post-tests. (a) Group 1 (Fall 2017); (b) Group 2 (Fall 2018); (c) Group 3 (Fall 2019); and, (d) All groups combined.

directly comparable between these previous homework assignments and the post-test. Proficiency scores on a 0.0 - 5.0 scale are provided below for comparison with the post-test results:

1. Descriptive statistics $-3.90 / 5.0$

2. Summing random variables $-\mathrm{n} / \mathrm{a}$

3. Standard normal distribution $-4.03 / 5.0$

4. Confidence intervals $-3.63 / 5.0$

5. Z-test of equality $-3.24 / 5.0$

6. Chi-square test $-1.68 / 5.0$

Notice that proficiency scores on the post-test are generally superior for Descriptive Statistics (4.66 vs. 3.90) and the Chi-square test (2.89 vs. 1.68). Proficiency scores on the post-test are lower for Standard normal distribution (3.21 vs. 4.03), Confidence intervals (1.82 vs. 3.63) and Z-test of equality (2.83 vs. 3.24). However, it should be noted that the homework assignments were graded by hand and generally included partial credit, whereas the post-test scores were 
graded automatically and did not include any partial credit. Thus, we would generally expect that the post-test scores to be lower than the homework assignment scores. The fact that some topics have higher scores and that other topics have scores within the same magnitude suggests that the intervention exhibits similar success as including the prerequisite material directly into the course.

Paired t-tests were performed on the pre- and post-test proficiency scores to determine if the changes observed were statistically significant; see Table 1. Across the entire dataset, significant, except for cases where changes in proficiency were small due to the relatively small sample sizes during each semester. improvements in all topic areas except for Topic 2 exhibited a statistically significant change in proficiency due to the intervention. Changes in individual groups were mostly statistically

Table 1. T-tests of differences between pre- and post-test proficiency scores.

\begin{tabular}{|c|c|c|c|c|c|c|}
\hline Group & $\begin{array}{c}\text { \# of } \\
\text { students }\end{array}$ & Topic & $\begin{array}{r}\text { Average } \\
\text { difference } \\
\end{array}$ & $\begin{array}{c}\text { Std. dev. in } \\
\text { difference }\end{array}$ & t-statistic & $\mathrm{p}$-value \\
\hline \multirow{6}{*}{1} & \multirow{6}{*}{29} & 1 & 0.10 & 0.10 & 1.00 & 0.163 \\
\hline & & 2 & 0.78 & 0.43 & 1.80 & 0.042 \\
\hline & & 3 & 1.55 & 0.56 & 2.77 & 0.005 \\
\hline & & 4 & 0.26 & 0.34 & 0.77 & 0.224 \\
\hline & & 5 & 1.03 & 0.44 & 2.35 & 0.013 \\
\hline & & 6 & 2.03 & 0.46 & 4.41 & 0.000 \\
\hline \multirow{6}{*}{2} & \multirow{6}{*}{30} & 1 & 0.67 & 0.15 & 4.33 & 0.000 \\
\hline & & 2 & 0.00 & 0.38 & 0.00 & 0.500 \\
\hline & & 3 & 1.83 & 0.56 & 3.27 & 0.001 \\
\hline & & 4 & 0.42 & 0.38 & 1.09 & 0.141 \\
\hline & & 5 & 1.87 & 0.41 & 4.60 & 0.000 \\
\hline & & 6 & 2.30 & 0.31 & 7.30 & 0.000 \\
\hline \multirow{6}{*}{3} & \multirow{6}{*}{22} & 1 & -0.18 & 0.16 & -1.16 & 0.871 \\
\hline & & 2 & 0.11 & 0.51 & 0.22 & 0.412 \\
\hline & & 3 & 1.59 & 0.61 & 2.63 & 0.000 \\
\hline & & 4 & 0.80 & 0.42 & 1.91 & 0.035 \\
\hline & & 5 & 1.36 & 0.47 & 2.92 & 0.004 \\
\hline & & 6 & 2.50 & 0.41 & 6.03 & 0.000 \\
\hline \multirow{6}{*}{ All } & \multirow{6}{*}{81} & 1 & 0.23 & 0.09 & 2.66 & 0.005 \\
\hline & & 2 & 0.31 & 0.25 & 1.23 & 0.110 \\
\hline & & 3 & 1.67 & 0.33 & $\mathbf{5 . 0 7}$ & 0.000 \\
\hline & & 4 & 0.46 & 0.22 & 2.15 & 0.017 \\
\hline & & 5 & 1.43 & 0.25 & 5.68 & 0.000 \\
\hline & & 6 & 2.26 & 0.23 & 9.84 & 0.000 \\
\hline
\end{tabular}

Bolded values represent statistically significant differences at the $95 \%$ significance level 
Figure 2 Over the four data sets (groups 1, 2, 3 and combined), the correlation coefficient between proficiency and confidence values is 0.91 . This high correlation between proficiency and confidence values suggests that students' confidence in the prerequisite material is generally in line with their understanding of the material.

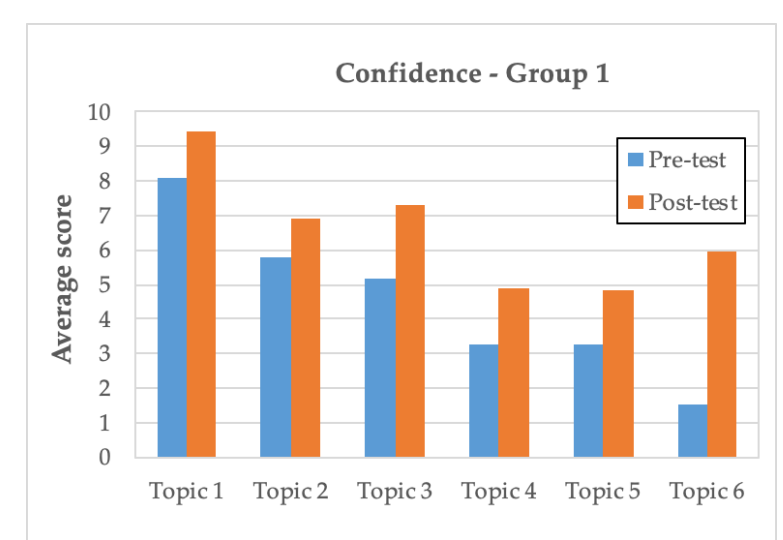

(a)

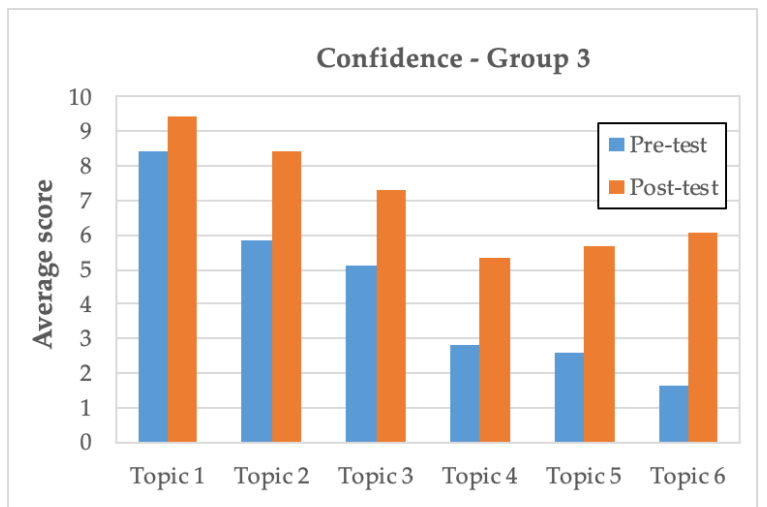

(c)

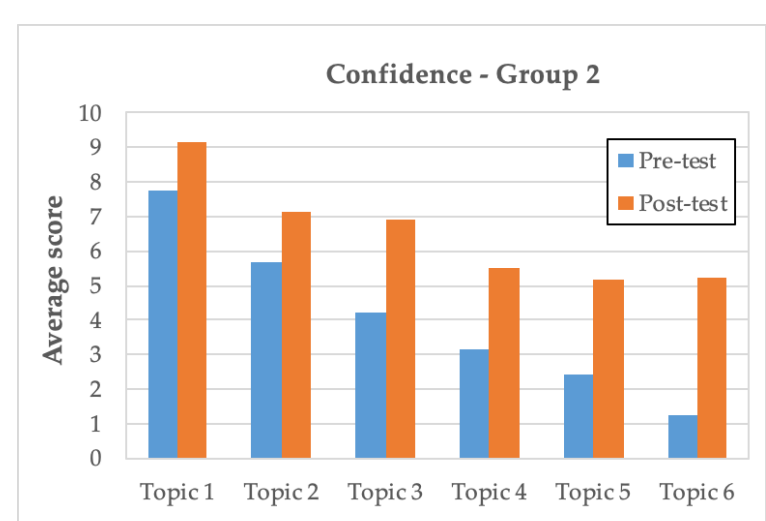

(b)

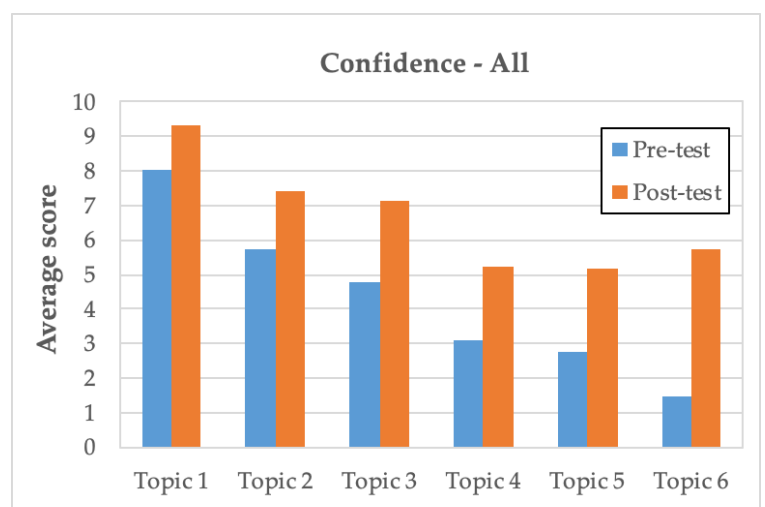

(d)

Figure 2. Comparison of student confidence scores within the various subject areas between pre- and post-tests. (a) Group 1 (Fall 2017); (b) Group 2 (Fall 2018); (c) Group 3 (Fall 2019); and, (d) All groups combined.

Confidence values on the pre-test ranged from very high in Topic $1(8.04 / 10.0)$ to very low in Topic 6 (1.46/10.0). Post-test scores show large improvements in confidence scores due to the intervention, including in topics that students already had high proficiency before the intervention (e.g., Topics 1 and 2). This suggests that the intervention can improve how confident students are applying topics that they generally already know very well entering the course. Focusing on the entire group of 81 students that received the intervention, the proposed intervention increased confidence levels by the following amounts:

1. Descriptive statistics - Increase of $16 \%$ 
2. Summing random variables - Increase of $29 \%$

3. Standard normal distribution - Increase of $49 \%$

4. Confidence intervals - Increase of $70 \%$

5. Z-test of equality - Increase of $88 \%$

6. Chi-square test - Increase of $292 \%$

In general, the results show only modest increases in areas in which students were exhibited strong proficiency levels before the intervention and large increases in areas that students were the weakest.

Paired t-tests were performed on the pre- and post-test confidence scores to determine if the changes observed were statistically significant; see Table 2 . Notice that all improvements were found to be statistically significant.

Table 2. T-tests of differences between pre- and post-test confidence scores.

\begin{tabular}{|c|c|c|c|c|c|c|}
\hline Group & $\begin{array}{c}\text { \# of } \\
\text { students }\end{array}$ & Topic & $\begin{array}{c}\text { Average } \\
\text { difference }\end{array}$ & $\begin{array}{l}\text { Std. dev. in } \\
\text { difference }\end{array}$ & t-statistic & p-value \\
\hline \multirow{6}{*}{1} & \multirow{6}{*}{29} & 1 & 1.31 & 0.23 & 5.75 & 0.000 \\
\hline & & 2 & 1.17 & 0.44 & 2.69 & 0.006 \\
\hline & & 3 & 2.10 & 0.53 & 4.00 & 0.000 \\
\hline & & 4 & 1.66 & 0.40 & 4.16 & 0.000 \\
\hline & & 5 & 1.59 & 0.46 & 3.44 & 0.001 \\
\hline & & 6 & 4.38 & 0.55 & 7.98 & 0.000 \\
\hline \multirow{6}{*}{2} & \multirow{6}{*}{30} & 1 & 1.43 & 0.33 & 4.28 & 0.000 \\
\hline & & 2 & 1.47 & 0.35 & 4.21 & 0.000 \\
\hline & & 3 & 2.70 & 0.51 & 5.27 & 0.000 \\
\hline & & 4 & 2.37 & 0.46 & 5.11 & 0.000 \\
\hline & & 5 & 2.77 & 0.69 & 4.02 & 0.000 \\
\hline & & 6 & 4.00 & 0.50 & 8.03 & 0.000 \\
\hline \multirow{6}{*}{3} & \multirow{6}{*}{22} & 1 & 1.05 & 0.25 & 4.18 & 0.000 \\
\hline & & 2 & 2.55 & 0.49 & 5.23 & 0.000 \\
\hline & & 3 & 2.23 & 0.50 & 4.45 & 0.035 \\
\hline & & 4 & 2.50 & 0.48 & 5.18 & 0.000 \\
\hline & & 5 & 3.09 & 0.33 & 9.23 & 0.000 \\
\hline & & 6 & 4.41 & 0.64 & 6.89 & 0.000 \\
\hline \multirow{6}{*}{ All } & \multirow{6}{*}{81} & 1 & 1.28 & 0.16 & 7.92 & 0.000 \\
\hline & & 2 & 1.65 & 0.25 & 6.71 & 0.000 \\
\hline & & 3 & 2.36 & 0.30 & 7.92 & 0.000 \\
\hline & & 4 & 2.15 & 0.26 & 8.30 & 0.000 \\
\hline & & 5 & 2.43 & 0.32 & 7.56 & 0.000 \\
\hline & & 6 & 4.25 & 0.32 & 13.38 & 0.000 \\
\hline
\end{tabular}




\section{Student engagement in course content}

The number of course lectures that were previously dedicated to covering the prerequisite material was used as a metric to determine how much class time was saved by using the intervention. In previous semesters of teaching this course, six of the thirty lecture periods (20\% of the course) were generally dedicated to statistics prerequisite material. By moving review of this material to outside the classroom, new topics that were never before covered in this course could be introduced. These new topics included signal coordination and a study of adaptive traffic signals, which are topics more directly related to traffic engineering than statistics. Two lecture periods were dedicated to each of these topics. In addition, two lectures were dedicated to in-class active learning exercises. These exercises included large problems that students solved in groups with the instructor's help. Such exercises have been shown to reinforce lecture material and facilitate learning. These in-class activities were specifically mentioned numerous times by students in teaching evaluations in response to the question: What helped you learn in this course? Sample responses included:

- In-class examples

- $\quad$ The in-class examples, with the solutions posted after.

- $\quad$ use of in class examples helps understand problems we would be doing.

- Very interactive class

- in class activities

- in class assignments

- Multiple in class activities

- example problems in class

- $\quad$ The various in-class examples helped me to learn in this course.

- In class examples helped to bring together the concepts discussed in lectures.

- The class examples

- The in-class participation problems helped me process the information that was conveyed in the slides

Notably, no negative feedback or comments were provided by students on the outside-of-theclassroom activities with respect to covering the prerequisite material, even though the instructor specifically asked students to provide feedback on these activities. Average student ratings on teaching evaluations also increased significantly after the introduction of this intervention. Average scores for Quality of the course increased from 5.98/7.0 to 6.23/7.0 and average scores for Quality of the instructor increased from 6.36/7.0 to 6.57/7.0. These scores were obtained from very high (at least a 75\%) response rates for all semesters on the teaching evaluations.

\section{Discussion and Conclusions}

This study found that personalized outside-of-the-classroom modules were able to increase both student proficiency and confidence in the prerequisite material without dedicating classroom time to these activities. While increases in proficiency may not have been as large as covering the material in the course, significant gains were still observed in several topic areas that students 
were the weakest in at the beginning of the semester. The intervention also increased student confidence in material that they were already generally proficient in, which helps reinforce existing knowledge. The intervention also increased student engagement in the course due to the ability to cover material more closely related to the course topic (as opposed to prerequisite material that was already covered in previous courses) and more time dedicated to in-class active learning activities. Thus, the results suggest that students can adequately address areas of weaknesses in prerequisite material on their own using outside-of-the-classroom interventions and removing coverage of prerequisite material from the classroom cause students to become more engaged in the actual course content.

The implications of this study to for other instructors are potentially very significant. The proposed methods can be readily applied to any other course that has well-defined prerequisite topics. Significant initial effort would be needed to carefully design the pre- and post-test to assess student proficiency, as well as to develop outside-of-the-classroom activities to cover these topics. Fortunately, the latter might be alleviated if resources already exist to cover this material; e.g., use of passages from textbooks or available online resources. It should be noted that students informally indicated that videos were more effective/preferred to textbook passages. For topics that do not have readily available resources, instructors would have to develop this on their own. However, this may not be problematic in courses where instructors already review the prerequisite material within the class and the materials that are developed can be reused in the future. In the long-run, this strategy appears to be a time-saving technique that allows instructors to focus more closely on the specific course material and implement more effective and engaging active learning activities within the classroom.

One limitation of the study was the sample size. The intervention was only performed in a single course over multiple years and included a total of just 80 students. Since this course only contained only one section, a comparison group was not available to examine differences compared to traditional methods of covering prerequisite material. Instead, only before and after data were available to assess the impacts. Changes in proficiency and confidence may have been influenced by other factors, such as topics covered in other courses. This is somewhat mitigated by the small time interval between the pre- and post-tests in this study (three weeks). Another limitation of the study is that the pre- and post-tests were developed by the lead course instructor, in order to best align with the objectives of the course. Therefore, there is no validity evidence for the pre- and post-test, beyond evidence based on test content. While this is a limitation, this is also common of other studies considered the Scholarship of Teaching and Learning (SOTL). Additional research should be conducted to carefully conduct psychometric analyses of the instruments, including the inclusion of validity evidence. Another limitation is the use of the same test at the beginning and end of the semester. It is possible that students learned from the test questions offered at the start of the semester, which primed them to focus on learning that material, which would influence their post-test performance. Furthermore, there are other confounding factors that may have influenced the results. For example, students could had taken different statistics courses to satisfy the statistics prerequisite or have taken this prerequisite course at different times before the subject course. However, since no large programmatic changes were made during the three-year study period, it is not likely that students would have had radically different changes in statistics preparation during this study period. 


\section{Acknowledgments}

This research was funded by a faculty project grant provided by the Leonhard Center for Enhancement of Engineering Education within the College of Engineering at the Pennsylvania State University.

\section{References}

[1] M. W. Ohland, A. G. Yuhasz, and B. L. Sill, "Identifying and Removing a Calculus Prerequisite as a Bottleneck in Clemson's General Engineering Curriculum," J. Eng. Educ., vol. 93, no. 3, pp. 253-257, Jul. 2004.

[2] J. J. Pembridge and M. A. Verleger, "First-year math and physics courses and their role in predicting academic success in subsequent courses," in 120nd American Society for Engineering Education (ASEE) Annual Conference \& Exposition, 2013.

[3] E. Schott and C. Orndoff, "Engineering Prerequisites at Florida Universities," in 2019 ASEE Annual Conference \& Exposition, 2019.

[4] R. E. Efimba and T. R. Smith, "Prerequisite Courses and retentivity as a Challenge for Students in Engineering Mechanics," in American Society for Engineering Education, 2012.

[5] A. Karimi and R. Manteufel, "Correlation of prerequisite course grades with student performance," in 120nd American Society for Engineering Education (ASEE) Annual Conference \& Exposition, 2013.

[6] J. Engelbrecht, A. Harding, and J. Du Preez, "Long-term retention of basic mathematical knowledge and skills with engineering students," Eur. J. Eng. Educ., vol. 32, no. 6, pp. 735-744, Dec. 2007.

[7] C. Breen and F. Faulkner, "How well do engineering students retain core mathematical knowledge after a series of high threshold online mathematics tests?"

[8] O. N. Kwon, C. Rasmussen, and K. Allen, "Students' Retention of Mathematical Knowledge and Skills in Differential Equations," Sch. Sci. Math., vol. 105, no. 5, pp. $227-$ 239, May 2005.

[9] K. A. Ericsson, Development of professional expertise: Toward measurement of expert performance and design of optimal learning environment. Cambridge University Press, 2009.

[10] C. R. Bego, K. B. Lyle, P. A. Ralston, and J. L. Hieb, "Retrieval practice and spacing in an engineering mathematics classroom: Do the effects add up?," in Proceedings Frontiers in Education Conference, FIE, 2017, vol. 2017-October, pp. 1-5.

[11] S. B. Velegol, S. Zappe, and M. L. Brannon, "Online modules enable prerequisite review and mastery during design courses," in 121st American Society for Engineering Education (ASEE) Annual Conference \& Exposition, 2014.

[12] R. P. Roess, E. S. Prassas, and W. R. McShane, Traffic Engineering, 4th Edition. 2010. 